\title{
DIAGNÓSTICO DERMATOLÓGICO EM PEQUENOS ANIMAIS: O QUE PODE INFLUENCIAR?
}

\author{
(Dermatological diagnostic in small animal: what can influence?)
}

Renata Madureira, Juliana Sperotto Brum

Programa de Pós-graduação em Ciências Veterinárias, Universidade Federal do Paraná, Curitiba, Paraná, Brasil.

*Correspondência: julianasbrum@yahoo.com.br

RESUMO: Muitas dificuldades são encontradas pelo clínico dentro da dermatologia veterinária. A análise de cada etapa a ser percorrida durante a consulta clínica evidenciará quais são os pontos críticos e auxiliará o médico veterinário na conclusão dos casos. O objetivo dessa revisão é abordar as principais influências no diagnóstico das doenças dermatológicas em pequenos animais. E essencial uma boa relação com o tutor, para que o mesmo forneça um bom histórico e assuma os custos dos exames complementares. Erros no diagnóstico ocorrem quando a anamnese é incompleta ou preenchida erroneamente, exame físico superficial ou feito às pressas e por avaliação precipitada ou falsa dos achados clínicos. A escolha dos exames complementares deve ser feita de maneira coerente, pois cada exame possui sua técnica adequada. Para a procura de Demodex sp. por meio da técnica de raspado cutânea, este deve ser realizada até as camadas mais profundas da pele. Na citologia, amostras de baixa qualidade ocorrem quando há muito sangue, pressão inadequada na punção, esfregaço espesso e tempo de contato com o corante insuficiente. A amostragem para cultura bacteriana não deve ser realizada de áreas com erosões úmidas e muitas crostas. O diagnóstico precoce de dermatofitose é necessário tanto para o início de um tratamento quanto para limitar o contágio com outros animais e pessoas. Na biópsia cutânea, as amostras devem ser de lesões precoces (lesões primárias) exceto, em doenças atróficas dos anexos. A boa comunicação com o tutor, atenção especial a todas as etapas da consulta clínica, não buscar resultados imediatos, fácil contato com o laboratório e os cuidados com a colheita de amostra para exames complementares influenciam de forma positiva no diagnóstico dermatológico.

Palavras-chave: Cães; custos; dermatologia; exames complementares; tutor

ABSTRACT: Many difficulties are encountered by the clinician within veterinary dermatology. The analysis of each step to be followed during the clinical consultation will show the critical points and assist the veterinarian in the conclusion of the cases. The objective of this review is to address the main influences in the diagnosis of dermatological diseases in small animals. A good relationship with the tutor is essential, so that it provides a good record and assumes the costs of the complementary exams. Errors in diagnosis occur when the anamnesis is incomplete or erroneously completed, superficial physical examination or hastily done and by precipitated or false evaluation of the clinical findings. The choice of complementary exams should be made in a coherent way, since each exam has its adequate technique. For the Demodex sp. by means of the skin scraping technique, this should be performed up to the deeper layers of the skin. In cytology, poor quality samples occur when there is too much blood, inadequate puncture pressure, thick smear and 
insufficient dye contact time. Sampling for bacterial culture should not be performed from areas with wet erosions and many crusts. Early diagnosis of dermatophytosis is necessary both for the initiation of a treatment and for limiting the contagion with other animals and people. In cutaneous biopsy, the samples must be of early lesions (primary lesions) except in atrophic diseases of the cutaneous appendages. Good communication with the tutor, special attention to all stages of the clinical consultation, not seeking immediate results, easy contact with the laboratory and the care with sample collection for complementary tests have a positive influence on the dermatological diagnosis.

Key Words: Dogs; costs; dermatology; complementary tests; tutor

\section{INTRODUÇÃO}

As doenças dermatológicas podem estar entre as condições mais gratificantes tratadas pelos veterinários ou as mais frustrantes (Paterson, 2008; Miller et al., 2013). Pacientes com lesões crônicas, tutores que relatam um histórico confuso e contraditório, dúvidas em quais exames complementares solicitar, tutores que negam a custear os exames, dificuldades na colheita da amostra e resultados negativos ou pouco esclarecedores dos exames podem desencorajar o clínico ao consultar pacientes com dermatopatias.

Inúmeras são as dificuldades, mas a análise de cada etapa a ser percorrida durante a consulta clínica evidencia quais são os pontos críticos desse contexto. E assim verificar o que é possível ser realizado para amenizar essas dificuldades. Com a utilização de uma abordagem orientada para 0 problema, diminuem-se as chances de que algum dado de anamnese ou sinal clínico importante passe despercebido; ao mesmo tempo em que aumenta a probabilidade de um diagnóstico correto e menos oneroso (Souza, 2009).

Embora existam tutores que possam priorizar o investimento com 0 tratamento de seus animais, como encontrado na pesquisa de Linek e Favot (2010), ainda existem aqueles que relutem em pagar os custos (Lorenz, 1996). Uma relação transparente com o tutor do paciente será essencial tanto para esclarecer sobre os gastos com exames quanto na obtenção de informações sobre a doença dermatológica. Obter um histórico clínico completo e estar atento às pistas fornecidas pelo tutor são habilidades que devem ser desenvolvidas pelo clínico (Scott et al., 2001).

$$
\text { As alterações cutâneas }
$$
geralmente são de fácil acesso para vários testes laboratoriais (Souza, 2009). Embora o exame clínico seja de grande valia, na maior parte dos casos ele, sozinho, não é suficiente para confirmar um diagnóstico; assim, exames complementares frequentemente são necessários (Scott et al., 2001). A avaliação dos sinais clínicos é imprescindível na escolha de qual exame complementar solicitar e qual o melhor momento para realizar esse exame.

Se após a avaliação do caso clínico ainda houver dúvidas quanto como proceder com a realização de exames complementares, então é indicado que o clínico busque auxílio de outros profissionais (parasitologista, microbiologista ou patologista). $\mathrm{Na}$ medicina veterinária, frequentemente, o laboratório de microbiologia é percebido apenas como um provedor de serviços e não como parte integrante de uma equipe de saúde, como deveria ser. Isso resulta em interação limitada entre microbiologistas e clínicos, diferindo de medicina humana onde os 
microbiologistas possuem maior interação com médico responsável pelo paciente (Guardabassi et al., 2017). A busca por instruções do profissional responsável pelo recebimento e processamento das amostras no laboratório é importante para diminuir os erros na fase pré-analítica. Essa fase corresponde à seleção, pelo clínico, de exames apropriados ao diagnóstico a que se pretende e à solicitação dos mesmos. Colheita, transporte e recepção das amostras adequadas ao exame, também devem estar inclusos nessa fase (Teixeira et al., 2011).

A maior causa de resultados inconclusivos nas biópsias cutâneas analisadas é a falta de informações fornecidas adequadamente ao patologista quanto à história, aparência clínica e outras informações pertinentes relacionadas a este tipo de exame (Miller et al., 2013). A maior interação entre os profissionais das áreas que envolvem a dermatologia (clínico, parasitologista, microbiologista e patologista) é uma das peças principais para a otimização do tempo em relação ao diagnóstico.

O objetivo dessa revisão é abordar as principais influências no diagnóstico das doenças dermatológicas em pequenos animais, desde o momento do histórico fornecido pelo tutor até a realização de exames complementares.

\section{DESENVOLVIMENTO}

\section{O diagnóstico de uma dermatopatia}

Segundo Feitosa (2008) o que constitui o diagnóstico nosológico ou clínico é o reconhecimento de uma doença com base nos dados obtidos na anamnese, no exame físico e/ ou exames complementares. Nutall et al. (2009) compara um caso clínico a um jogo de quebra-cabeça, onde o histórico, os achados clínicos e os procedimentos para o diagnóstico são as principais peças para a obtenção do diagnóstico definitivo.

O histórico fornecido pelo tutor é fundamental no início de uma consulta clínica. Um bom histórico pode determinar a progressão das lesões de pele e da doença dermatológica (Miller et al., 2013). O tempo é fator limitante mais importante quando se toma o histórico de um tutor (Paterson, 2008), portanto, quanto mais informações o clínico obter do tutor mais próximo estará do diagnóstico.

Se durante o exame físico do animal forem observadas anormalidades, é importante estabelecer as suas características morfológicas, configurações e distribuição geral (Scott et al., 1995). É relevante lembrar que muitos pacientes possuem uma doença primária a qual propicia infecções secundárias. Indica-se que essas infecções secundárias sejam tratadas, mas ela retornará caso a doença de base não for identificada ou controlada (Hnilica, 2011).

Os exames laboratoriais são úteis se um diagnóstico definitivo não puder ser feito apenas a partir da história do caso e do exame clínico. Deve-se, com a evolução do caso, tentar estabelecer o diagnóstico por exclusão, eliminando-se, aos poucos, algumas hipóteses diagnósticas inicialmente presumidas, pelas características do quadro sintomático e pela realização de exames complementares (Feitosa, 2008). Esses exames são capazes de confirmar muitos diagnósticos clínicos e fornecer uma base lógica para tratamento terapêutico bem sucedido (Scott et al., 2001).

\section{Relação clínico-tutor}

Assim como citado anteriormente, o tutor fornecerá as informações que vão compor a anamnese e assim podem interferir negativamente ou positivamente 0 trabalho do clínico veterinário. É importante avaliar o quanto 
precisas são as informações fornecidas pelo tutor. Esse por sua vez, pode induzir o clínico veterinário ao erro por falta de um histórico preciso (Paterson, 2008). Um exemplo de interferência positiva é quando este reconhece que 0 animal está com prurido acima do normal e consegue verificar a presença de alopecias ou áreas avermelhadas na pele do cão antes que as lesões tornemse generalizadas. Também atua de forma positiva quando busca por auxílio do médico veterinário especializado e executa todo o tratamento indicado pelo mesmo.

O meio mais barato para o clínico é instruí-lo sobre sinais e sintomas a observar. $O$ profissional pode desenvolver um melhor relacionamento com os clientes e obter informações essenciais treinando-os para o que devem observar, especialmente se houver uma recidiva ou resposta ruim a terapia (Miller et al, 2013).

Linek e Favot (2010) em estudo referente ao impacto da dermatite atópica canina na qualidade de vida dos cães e dos tutores, citam que os tutores relataram dificuldades de administração de medicamentos e que procedimentos consomem demasiado tempo. Em pesquisa semelhante, Ruivo (2015), relatou que os $72 \%$ (21/29) dos clínicos veterinários acreditam que os tutores compreendem "pouco" a cronicidade da doença e $76 \%$ (22/ 29) o fato de ser incurável.

A maioria dos tutores de uma cidade do interior do Rio de Janeiro, em estudo realizado (Silvano et al., 2010), relataram que quando seus cães se encontravam doentes reportam 0 problema ao balconista da farmácia ou do pet shop. Em pesquisa semelhante em uma cidade no interior do estado de São Paulo (Langoni et al., 2011), apenas $37,4 \%$ (37/99) dos proprietários controlam a infestação por pulgas de seus animais e somente $12,12 \%$ (12/99) controlam a infestação por carrapatos.

Infelizmente, em muitas regiões essa realidade não é muito diferente, por exemplo, em Botucatu, interior de São Paulo, mais da metade dos tutores não costumavam levar seus cães a uma clínica veterinária (Souza et al., 2002). Dessa forma, a falta de informação dos tutores aliado a falta de atendimento adequado, refletirá de forma negativa na resolução da doença dermatológica. Em contrapartida, a parceria entre veterinários e donos é de fato crucial para a boa saúde dos cães (Schneider et al., 2010). Essa aliança dentro do cenário dermatológico, aperfeiçoará a busca pelo diagnóstico definitivo assim como a otimização do tratamento dermatológico.

\section{Custos}

O valor da consulta, dos exames complementares e do tratamento, poderá influenciar diretamente sobre a decisão do tutor em buscar os serviços do médico veterinário. Segundo estudo realizado na cidade de Botucatu, 49,57\% dos tutores afirmaram não ter condições de pagar uma consulta veterinária e 44,69\% não gastam mais de $R \$ 20,00 /$ mês com seus animais (Souza et al., 2002). Linek e Favot (2010) em estudo referente ao impacto da dermatite atópica canina na qualidade de vida dos cães e dos tutores, cita que 68\% (34/50) dos tutores limitam outras despesas para poderem pagar 0 tratamento do seu cão.

Devido a essa baixa disponibilidade de recursos financeiros por parte dos tutores, muitos animais podem demorar muito tempo até a consulta dermatológica. Com o tempo, a distribuição, a configuração e o aspecto histopatológico das lesões modificam-se. Em muitos casos, o padrão que a doença de pele toma é inexplicável (Scott et al. 2001). E assim, o médico veterinário 
empregará mais tempo ao classificar essas lesões.

Com relação aos exames complementares, na prática, muitos clientes são relutantes em gastar dinheiro com exames, particularmente na ocorrência inicial de um problema (Miller et al. 2013).

Métodos de diagnóstico clínicos simples e baratos, que confirmem ou descartem qualquer das possibilidades mais prováveis (primeiras três ou quatro) de diagnósticos diferenciais, devem ser realizados (Scott et al., 2001). Amostras de pelo e da pele podem fornecer informações relevantes (Souza, 2009). O raspado cutâneo é um bom exemplo de um importante exame de baixo custo (Hnilica, 2011).

Testes diagnósticos ou métodos mais complexos ou caros são recomendados em seguida. Os clientes podem escolher renunciar esses testes e buscar diagnósticos diferenciais menos prováveis na tentativa de economizar. Frequentemente, esta abordagem não é econômica, quando se considera as despesas com medicamentos ineficazes e exames repetidos (Scott et al., 2001). Uma melhor aceitação dos custos associados ao futuro tratamento é obtida por meio do desprendimento de tempo orientando o tutor (Miller et al., 2013).

Outro fator possivelmente relevante em relação aos custos de exames laboratoriais na medicina veterinária é a menor demanda em relação aos exames laboratoriais em humanos. A utilização limitada de exames microbiológicos em práticas veterinárias tem consequências negativas sobre os custos, com estes sendo até três vezes superiores aos custos de exames comparáveis no setor de saúde humana (Guardabassi et al., 2017).

\section{Busca por resultado imediato}

O tempo é sempre o fator limitante mais importante quando se toma uma história de um tutor. Frequentemente é tentador prescrever um tratamento sintomático durante uma clínica movimentada, entretanto, existe a opção de prescrever fármacos como antibióticos, anti-histamínicos e terapia tópica sob a forma de xampus os quais raramente vão complicar um diagnóstico em uma data posterior. A resposta de um paciente a esses tratamentos muitas vezes pode ajudar no direcionamento de mais testes (Paterson, 2008), assim como controlam infecções secundárias. Como exemplo, podemos citar a piodermite bacteriana secundária, a qual leva mudanças histopatológicas que podem obscurecer achados histopatológicos de dermatoses primárias (Miller et al., 2013).

Corticoterapia

sintomática raramente é indicado, pois pode afetar dramaticamente a aparência histológica em muitas dermatoses (Miller et al., 2013) e muitas vezes torna impossível maiores investigações a curto prazo (Paterson, 2008).

Idealmente, um exame completo e procedimentos apropriados de diagnóstico são executados na primeira vez que se observa o paciente e antes que qualquer tratamento tenha sido iniciado (Miller et al., 2013).

Erros no diagnóstico ocorrem quando a anamnese é incompleta ou preenchida erroneamente, exame físico superficial ou feito às pressas, avaliação precipitada ou falsa dos achados clínicos, conhecimento ou domínio insuficiente dos métodos dos exames físicos disponíveis e impulso precipitado em tratar o paciente antes mesmo de se estabelecer 0 diagnóstico (Feitosa, 2008).

Tanto o tutor quanto o clínico devem estar cientes de que muitas doenças dermatológicas possuem 
tratamentos longos e dependem da dedicação dos mesmos. Enfim, a procura pela resolução rápida da doença pode levar a melhoras momentâneas com piora do quadro posteriormente ou a numerosos efeitos colaterais.

\section{Exames complementares}

A escolha dos exames complementares a serem realizados deve ser feita de maneira coerente, com base nos achados clínicos e nos diagnósticos diferenciais previamente estabelecidos (Souza, 2009). Quando estes exames são realizados posteriormente ao exame físico do animal, aumentam acentuadamente as possibilidades de se identificar com precisão e rapidez as modificações orgânicas provocadas por diferentes enfermidades (Feitosa, 2008).

Para o diagnóstico dermatológico existem vários exames complementares que o clínico pode utilizar. Os exames laboratoriais mais utilizados na rotina dermatológica incluem: exame parasitológico, exame citológico, exame bacteriológico, exame micológico e exame histopatológico (Souza, 2009).

Cada exame possui sua técnica adequada de colheita de amostra assim como o melhor momento para a realização do mesmo e/ou o local de amostragem.

\section{Exame parasitológico}

Uma das técnicas utilizadas para a pesquisa de parasitas é o raspado cutâneo, a qual é uma das técnicas mais comuns na dermatologia veterinária. Eles são relativamente simples e rápidos e podem ser usados para identificar muitos tipos de infecções parasitárias (Hnilica, 2011).

Para a procura de Demodex sp. por meio da técnica de raspado cutânea, esta deve ser realizada até as camadas mais profundas da pele (Paterson, 2008; Hnilica, 2011; Miller et al., 2013). Em locais em que a realização de raspado cutâneo profundo possa ser difícil, como áreas perioculares, perilabiais ou interdigitais, o tricograma pode ser uma opção (Gortel, 2006). Saridomichelakis et al. (2007) ressaltaram que, apesar de atraumático e de fácil execução, o tricograma pode fornecer resultados falso-negativos, especialmente em cães com demodicidose localizada e pequena carga parasitária. Os raspados cutâneos em áreas de pele espessa, podem resultar em falsos-negativos para pesquisa de Demodex sp. (Paterson, 2008).

\section{Exame citológico}

A citologia é um método confiável para a obtenção de um diagnóstico sobre um tecido de forma minimamente invasiva (Meinkoth et al., 2009). O tipo de infiltrado inflamatório, neoplásico ou outro celular; a quantidade relativa de proteína ou mucina; e a presença de queratinócitos acantolíticos, leveduras e bactérias podem ser determinadas por avaliação citológica (Miller et al., 2013).

A colheita de material para citologia da pele pode ser realizada de forma esfoliativa, por impressão direta no tecido (imprint), por raspado cutâneo ou com auxílio de suabe, ou por punção, com ou sem aspiração (Rocha, 2008). A escolha do melhor método será dependente do padrão lesional. A impressão direta do tecido (imprint) pode ser feita em lesões ulceradas e exsudativas para pesquisa de bactérias ou fungos, entretanto, não há esfoliação de muitas células em tecidos de textura fibrosa, como por exemplo fibromas, fibrossarcoma e inflamações cicatriciais (Meyer et al., 2011).

A qualidade das amostras pode ser prejudicada quando (Meinkoth et al., 2009; Meyer et al., 2011): 
- Estão com excesso de sangue principalmente, pelo uso de agulhas de calibre alto ou por aspiração prolongada;

- Há baixa celularidade devido a pressão negativa inadequada e penetração lenta ou superficial da agulha;

- Há falhas no processamento do material (alteração de coloração por amostra espessa na lâmina, tempo de contato com o corante insuficiente, demora na fixação e exposição da amostra ao formol ou ao seu vapor).

O uso bem-sucedido da citologia depende de diversos procedimentos inter-relacionados: obtenção de amostra representativa, aplicação apropriada à lâmina, coloração adequada e exame em um microscópio de qualidade (Meyer et al., 2011).

\section{Exame bacteriológico}

A pesquisa por bactérias pode ser realizada por meio do exame citológico ou por cultura. Esse método tornou-se a ferramenta mais importante em investigação, especialmente a partir do momento que foram identificados em pequenos animais a resistência à meticilina de isolados de Staphylococcus aureus (Paterson, 2008). Em geral, a cultura bacteriana é indicada nos casos em que a citologia revela microorganismos em forma de cocos ou bastonetes e o tratamento apropriado foi ineficaz (Scott et al., 2001). É necessária uma seleção da amostra e o acondicionamento adequado da mesma para ser encaminhada para cultura, pois o resultado será tão bom quanto a qualidade da amostra que foi enviada ao microbiologista (Wilkinson e Harvey, 1996).

Erosões úmidas e muitas crostas podem ser contaminadas pelo crescimento excessivo bacteriano e as culturas podem ser difíceis de interpretar para essas lesões (Miller et al., 2013). Nas pústulas deve-se coletar o material com agulha estéril e transferi-lo para um suabe estéril (Miller et al., 2013) ou então solução salina estéril e entregue ao laboratório 0 mais rápido possível (Paterson, 2008). A desinfecção da superfície de pápulas e pústulas não é recomendada antes da colheita de amostra para cultura, porque isso pode resultar em ausência de crescimento bacteriano na cultura (Miller et al., 2013). Em dermatites bacterianas profundas, a amostras de lesões profundas são melhor colhidas como amostras estéreis de biópsia (Paterson, 2008). Quando colhido por meio de biópsia fragmentos para cultura, não deve ser utilizado anestésico local, devido ao fato que a lidocaína inibe o crescimento de várias bactérias gram positivas (incluindo o Staphylococcus coagulase positivo) e gram negativas (incluindo Pseudomonas sp.), micobactérias e fungos. (Miller et al., 2013). Sempre que possível, entrar em contato com o laboratório o qual pretende enviar a amostra. O laboratório de microbiologia deve desempenhar um papel importante no diagnóstico de doenças infecciosas, fornecendo suporte para várias etapas do processo de diagnóstico, desde a coleta e transporte de material até a interpretação dos resultados do antibiograma (Guardabassi et al., 2017).

\section{Exame micológico}

A pesquisa por fungos pode ser realizada por exame direto ou cultura. No exame direto é realizada a pesquisa, com o microscópio óptico, por artroconídeos, leveduras, hifas ou pseudo-hifas em amostras de pelos que estejam quebrados ou deformados e associados à inflamação, descamação ou crostas (Souza, 2009).

A cultura fúngica para pesquisa de dermatófitos deve ser realizada em 
qualquer doença inflamatória da pele canina e qualquer problema de pele felina (Paterson, 2008). O diagnóstico precoce dessas afecções cutâneas é necessário tanto para o início de um tratamento quanto para limitar o contágio com outros animais e pessoas (Moriello et al., 2017).

Alguns fatores podem interferir na confirmação da infecção fúngica. $O$ primeiro é que pelos infectados podem ser obscurecidos por inflamação e crostas. Este problema é agravado por tratamentos prévios que podem mudar a aparência das lesões e/ou por uma dificuldade de colher o material para o exame (Moriello et al., 2017). Outros resultados falsos negativos da cultura fúngica podem ser de amostragem insuficiente, particularmente quando os pelos são arrancados (Sparkes et al., 1993). O segundo é a ocorrência de falsos positivos pela exposição de objetos contaminados inanimados na cultura a ser testada ou a contaminação da amostra com pelos de outro animal infectado (Moriello et al., 2017). Seguir a metodologia adequada para a colheita da amostra é necessário para minimizar a possibilidade de falsos resultados.

\section{Exame histopatológico}

O exame histopatológico para alguns autores (Conceição et al., 2004), pode ser soberano, definitivo ou, no mínimo, auxilia o clínico a diminuir a lista dos possíveis diagnósticos diferenciais. Nas afecções cutâneas o exame histopatológico é indicado para (Paterson, 2008; Miller et al., 2013):

- Aumento de volume cutâneo com suspeita de neoplasia;

- Dermatopatias que não estejam respondendo ao tratamento aparentemente racional;

- Todas as lesões vesiculares ou ulcerações persistentes;

- Toda dermatose com suspeita de doença rara ou pareça séria;
- Toda condição suspeita cujo tratamento é caro, perigoso ou demorado o suficiente para que seja necessário um diagnóstico definitivo antes de ser iniciado.

Apesar de diversas indicações, as biópsias de pele não são frequentemente realizadas ou são feitas relativamente tarde na investigação diagnóstica. Em outros casos, os achados da biópsia são não recompensadores por causa da amostra selecionada de má qualidade ou uma técnica ruim, ou ambos (Miller et al., 2013). Ao contrário disto, esse método de diagnóstico fornecerá muitas informações se for realizada uma amostragem apropriada. Idealmente, as amostras devem ser de lesões precoces e aonde possíveis lesões primárias devem ser biopsiadas (Paterson, 2008). A amostra deve ser representativa da doença e para isso o clínico deve obter amostras de várias lesões (Yager e Wilcock, 1994; Hargis e Ginn, 2007). Em algumas regiões do corpo do animal as lesões podem se tornar crônicas e o infiltrado inflamatório pode mascarar algumas doenças de base. Em cães com suspeita de dermatite atópica, as áreas crônicas de liquinificação e hiperpigmentação, as quais são mais acometidas por piodermite secundária e/ou dermatite por Malassezia pachydermatis, devem ser evitadas (Gross et al. 2009). Entretanto nem sempre as lesões recentes são mais indicadas para serem biopsiadas (Yager e Wilcock, 1994; Scott et al., 2001), e o local indicado para a amostragem provém da suspeita clínica. Como por exemplo, nas doenças atróficas dos anexos, nas quais a biópsia deverá sempre ser feita das lesões alopécicas e consequentemente mais antigas (Gross et al., 2009).

A maximização dos potenciais benefícios dessa ferramenta necessita de um trabalho em equipe entre o clínico quem, com cuidado, selecionar, 
pesquisar e preservar a amostra e o patologista quem, com cuidado, processar, ler e interpretar as amostras (Miller et al., 2013).

\section{CONCLUSÃO}

A interação com o tutor influencia no diagnóstico tanto de forma direta na colheita de dados em relação ao histórico quanto de forma indireta autorizando a realização dos exames complementares. Ter em mente de forma organizada todas as etapas de uma consulta clínica assim como a importância de cada etapa (anamnese, exame físico e realização de exames complementares) e evitar a busca por resultados imediatos pode minimizar as chances de possíveis erros no diagnóstico. É importante avaliar os possíveis exames a serem realizados em relação aos sinais clínicos do paciente e também como minimizar a possibilidade de resultados falsos positivos, falsos negativos e inconclusivos. Enfim, a comunicação do clínico com os laboratórios (parasitologia, microbiologia e patologia) influencia de forma positiva no diagnóstico, melhorando a qualidade das amostras e dos resultados.

\section{AGRADECIMENTOS}

À Coordenação de Aperfeiçoamento de Pessoal de Nível Superior (CAPES) pela concessão de bolsa de mestrado.

\section{REFERENCIAS}

CONCEICAO, L.G.; LOURES, F.H.; FABRIS, V.E. Biópsia e histopatologia da pele: um valioso recurso diagnóstico na dermatologia - revisão - parte 1. Clínica Veterinária, s/v, n. 51, p. 36-44, 2004.

FEITOSA, F. L.F. Introdução à Semiologia. In: Semiologia Veterinária: A arte do Diagnóstico. 2 ed. São Paulo: Roca, 2008. Cap.1., p. 314.

GORTEL, K. Update on canine demodicosis. Veterinary Clinics: Small Animal Practice, v.36, n.1, p.229-241, 2006.

GROSS, T.L.; IHRKE, P.J.; WALDER, J.E et al. Doenças atróficas dos anexos. In:

gato: diagnóstico clínico e histopatológico. 2 ed. São Paulo: Roca, 2009. Cap.19., p.464-501.

GUARDABASSI, L.; DAMBORG, P.; STAMM, I. et al. Diagnostic microbiology in veterinary dermatology: present and future. Veterinary Dermatology, v.28, n.1, p.146e30, 2017.

HARGIS, A. M.; GINN, P. E. The integument. In: McGAVIN M. D.; ZACHARY, J. F. (Org.). Pathologic basis of veterinary disease. 4th. ed. St. Louis: Mosby Elsevier, 2007. p.11071261.

HNILICA, K. A. Small animal dermatology: a color atlas and therapeutic guide. 3. ed. St. Louis: Elsevier, 2011,611 p.

LANGONI, H.; TRONCARELLI, M.Z.; RODRIGUES, E.C. et al. Conhecimento da população de botucatu-sp sobre guarda Responsável de cães e gatos. Veterinária e Zootecnia, v.18, n.2, p.297305, 2011.

LINEK, M.; FAVROT, C. Impact of canine atopic dermatitis on the health-related quality of life of affected dogs and quality of life of their owners. Veterinary Dermatology, v.21, n.15, p.456-462, 2010.

LORENZ, M. D. Abordagem orientada para o problema. In: LORENZ, M. D. CORNELIUS, L. M. (Org.). Diagnóstico 
clínico em pequenos animais. 2. ed. Rio de Janeiro: Interlivros, 1996. p. 1-11.

MEINKOTH, J.H; COWELL, R. L.; TYLER, R.D. et al. Coleta e prepare de amostras. In: COWELL, R. L.; TYLER, R.D.; MEINKOTH, J.H. et al. Diagnóstico citológico e hematológia de cães e gatos. 3 ed. São Paulo: Medvet, Cap. 1., p.1-19, 2009.

MEYER, D.J.; CONNOLY, S.L.; HENG, H.G. Obtenção e manuseio de amostras citológicas. In: RASKIN, R.E.; MEYER, D.J. Citologia clínica de cães e gatos: atlas colorido e guia de interpretação. 2 ed. Rio de Janeiro: Elsevier, Cap.1., p.1-14, 2011.

MILLER JR, W.H.; GRIFFIN, C.E.; CAMPBELL, K. L. Diagnostic Methods. In:_. Muller \& Kirk Small Animal Dermatology. 7 ed. St. Louis: Elsevier, 2013. Cap.2., p. 92-95.

MORIELLO, K. A.; COYNER, K., PATERSON, $S$. et al. Diagnosis and treatment of dermatophytosis in dogs and cats.: Clinical Consensus Guidelines of the World Association for Veterinary Dermatology. Veterinary Dermatology, v.28, n.3; p.266-e68, 2017.

NUTTALL, T., HARVEY, R. G.; MCKEEVER, P.J. A Colour Handbook of Skin Diseases of the Dog and Cat. 2.ed. London: Manson, 2009, 336 p.

PATERSON, S. Manual of the skin diseases of the dog and cat. 2.ed. Oxford: Blackwell, 2008. p. 1-22.

ROCHA, N. S. Exame citológico no diagnóstico de lesões da pele e subcutâneo. Clínica Veterinária, s/v, n. 76, p. 76-80, 2008.

SCHNEIDER, T. R.; LYONS, J. B.; TETRICK, M. A. et al. Multidimensional quality of life and human-animal bond measures for companion dogs. Journal of Veterinary Behavior, v. 5, n. 6, p. 287-301, 2010.

SARIDOMICHELAKIS, M. N.; KOUTINAS, A.F.; FARMAKI, R. et al. Relative sensitivity of hair pluckings and exudate microcopy for the diagnosis of canine demodicosis. Veterinary Dermatology, v.18, n.2, p.138141, 2007.

SCOTT, D. W.; MILLER, W. H.; GRIFFIN, C. E. Muller \& Kirk Small Animal Dermatology. 6.ed. Philadelphia: W.B. Saunders, 2001, 1528 p.

SILVANO, D.; BENDAS, A.J.R.; MIRANDA, M.G.N. et al. Divulgação dos princípios da guarda responsável: uma vertente possível no trabalho de pesquisa a campo. Revista Eletrônica Novo Enfoque, Rio de Janeiro, v. 9, n. 9, p. 64-86, 2010.

SPARKES, A. H.; GRUFFYDD-JONES, T.J.; SHAW, S.E. et al. Epidemiological and diagnostic features of canine and feline dermatophytosis in the United Kingdom from 1956 to 1991. The Veterinary Record; v.133, n.3, p. 57-61, 1993.

SOUZA, L. C.; MADOLO, J. R.; PADOVAN, $C$. $R$. et al. Posse responsável de cães no Município de Botucatu - SP: realidades e desafios. Revista Educação Continuada do CRMV-SP, São Paulo, v. 5, n. 2, p. 226232, 2002.

SOUZA, T. M. Dermatopatias nãotumorais em cães: bases para 0 diagnóstico e dados de prevalência em Santa Maria, Rio Grande do Sul (2005-2008). 2009. Santa Maria, 167f. Tese (Doutorado em Patologia Veterinária) - Centro de Ciências Rurais, Universidade Federal de Santa Maria. 
VIEIRA, K.F.; SHITARA, E.S.; MENDES, $M$.E. et al. A utilidade dos indicadores da qualidade no gerenciamento de laboratórios clínicos. Jornal Brasileiro de Patologia e Medicina Laboratorial, v.47, n.3, p.201-210, 2011.

WILKINSON, G. T.; HARVEY, R. G. Atlas colorido de dermatologia dos pequenos animais. Guia para 0 diagnóstico. 2. ed. São Paulo: Manole, 1996. $304 \mathrm{p}$.

YAGER, J. A.; WILCOCK, B. P. Color atlas and text of surgical pathology of the dog and cat. Dermatopathology and skin tumors. London: Wolfe, 1994. $320 \mathrm{p}$. 